\title{
Babesiosis acquired from a pet dog: a second reported case in Hong Kong
}

Jacky MC Chan *, FHKCP, FHKAM (Medicine), KY Tsang, FHKAM (Medicine), FRCP (Glasg \& Edin),

Thomas SH Chik, MB, ChB, MRCP(UK), WS Leung, FHKCP, FHKAM (Medicine), Owen TY Tsang, FHKAM (Medicine), FRCP (Edin)

Department of Medicine and Geriatrics, Princess Margaret Hospital, Laichikok, Hong Kong

* Corresponding author: cmc061@ha.org.hk

Hong Kong Med J 2016;22:393-5

DOI: $10.12809 / \mathrm{hkmj} 144390$

\section{Case report}

A 61-year-old Chinese man was admitted to our hospital in June 2012 with a 2-week history of fever and chills. After admission, he developed hypotension and respiratory distress and was transferred to the intensive care unit (ICU) for further management.

He frequently commuted between New York, Hong Kong, and Shanghai for business. He lived in his own house in New York and had a dog. Three weeks before onset of his symptoms, he swept his basement where his dog spent most of its time. He was not aware of any tick bite.

He was a chronic smoker but enjoyed good past health. His symptoms began with fever and chills while in China. He also experienced malaise and a mild dry cough. He had no skin rash, or abdominal or urinary symptoms. A diagnosis of upper respiratory tract infection was made and he was given a course of piperacillin-tazobactam during hospitalisation in China. Symptoms persisted, however, and he presented to a public hospital in Hong Kong. Initial blood tests revealed a normochromic normocytic anaemia (haemoglobin, $81 \mathrm{~g} / \mathrm{L}$ ) with reticulocytosis, marked thrombocytopenia, and moderate renal impairment. Blood smear revealed the presence of intra-erythrocytic ring-form parasites, suggestive of Plasmodium falciparum infection (Fig 1). Chest $\mathrm{X}$-ray showed bilateral extensive abnormal lung infiltrates. He was transferred to our hospital for further management.

He soon developed shock and was transferred to the ICU. Further blood tests revealed hyperbilirubinaemia and evidence of haemolysis. Peripheral blood smear for malaria was repeated and revealed $3.8 \%$ parasitised red cells. Pleomorphic ring forms were noted, with occasional arrangement in a cross-like pattern (Fig 2). Rapid antigen test for $P$ falciparum was negative and this raised the suspicion of babesiosis. A subsequent blood Babesia microti polymerase chain reaction (PCR) test was positive and a diagnosis of babesiosis was confirmed.

Quinine and clindamycin were initiated. The patient experienced severe tinnitus after 5 days of treatment and quinine was stopped. Doxycycline was added for treatment due to persistent fever and because it is known that Lyme's disease can be a concurrent infection. He stayed in the ICU for 6 days and his condition was stabilised with resolution of fever. Blood smear for Babesia turned negative on day 14 of treatment. Supportive blood transfusion

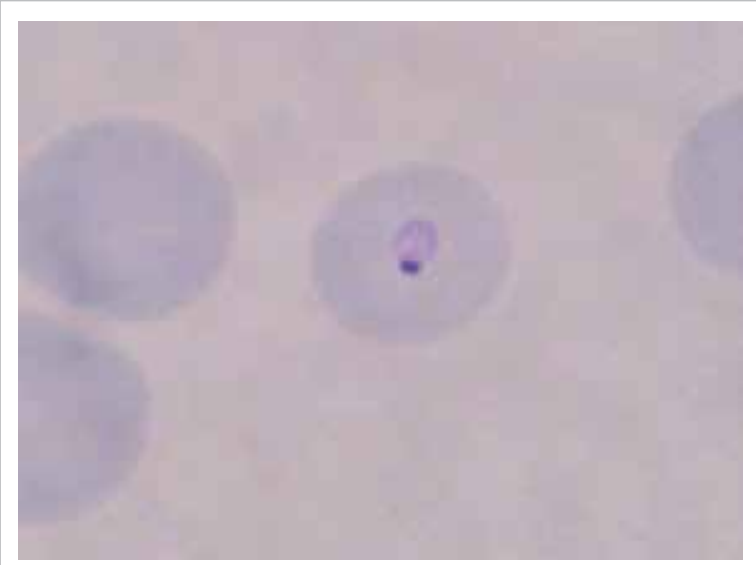

FIG I. Intra-erythrocytic ring-form trophozoite in thin blood smear (Giemsa stain; original magnification, x 100)

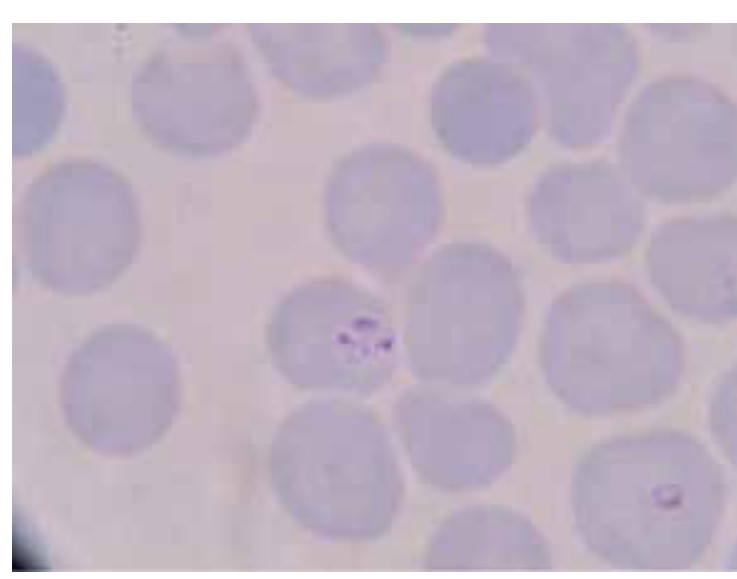

FIG 2. Babesia microti in thin blood smear (Giemsa stain; original magnification, $x$ 100). Tetrads of merozoites are arranged in a cross-like pattern (Maltese cross) 
was given for anaemia and the patient was discharged after 21 days.

He attended regular follow-ups in our clinic. Repeated blood smear for babesiosis and Babesia PCR test (in September 2012, 3 months after treatment) were negative. He had the basement of his New York apartment professionally cleaned and had his dog treated for ticks.

\section{Discussion}

This is the second imported case of human babesiosis in Hong Kong since 2007. ${ }^{1}$ Babesiosis is a tick-borne disease in which patients are infected with intraerythrocytic parasites of the genus Babesia. The common species affecting humans are $B$ microti and Babesia divergens, mostly found in the United States and Europe, respectively. White-footed mice are the primary reservoir host, but other small rodents may also carry $B$ microti. The Babesia parasites are transmitted to humans accidentally by Ixodid tick bites. In the United States, Ixodes scapularis is the most common vector. The ticks become infected with $B$ microti when they feed on vertebrate reservoir hosts such as infected white-footed mice and whitetailed deer. Humans are usually accidental hosts. ${ }^{2}$

The diagnosis of human babesiosis is made by microscopic examination of Giemsa-stained thick and thin blood smears. Microscopically, Babesia species may appear as round or oval-shaped forms, with blue cytoplasm and red chromatin. Multiple parasites may be present in a single-infected red blood cell. Differentiation of the ring-form of Babesia species and $P$ falciparum may be difficult. Some distinguishing features of babesiosis include the presence of extra-erythrocytic forms in severe cases and the absence of pigment deposits typically seen in older ring stages of $P$ falciparum. The Maltese cross pattern in which tetrads of merozoites are arranged is pathognomonic of babesiosis, but they are not commonly seen. ${ }^{3}$ Nonetheless, the different species of babesiosis cannot be distinguished by microscopic examination. Real-time PCR performed on DNA targeting the 18S rRNA gene of $B$ microti is therefore a more specific and accurate method to detect $B$ microti. ${ }^{4}$

Our patient was a case of possible petassociated human Babesia infection. Babesiosis is a zoonotic protozoan disease of medical, veterinary, and economic importance. A case of human babesiosis acquired from a pet $\operatorname{dog}$ has been reported where the dog was heavily infested with ticks. ${ }^{5}$ In a Brazilian evaluation of ectoparasites in dogs kept in apartments, Ixodid nymphs were found in $2 \%$. In houses with grassy yards, $18 \%$ of pet dogs were found to carry Ixodid nymphs. ${ }^{6}$ Different species of Ixodid ticks have been identified in dogs, with the head being the most common site of attachment. The activity of tick attachment peaks in spring and in autumn. Canine babesiosis is diagnosed by veterinarians in approximately $20 \%$ of tick-infested dogs. ${ }^{7}$ In one study in New York state, I scapularis ticks were collected from recreational lands to determine the prevalence and distribution of tickborne pathogens. The overall prevalence of $B$ microt $i$ was approximately $3 \%$ among both nymphs and adult ticks. ${ }^{8}$

In Hong Kong, around 250000 households are estimated to keep dogs or cats, representing $10.6 \%$ of all households. ${ }^{9}$ There has been no single reported case of human babesiosis in Hong Kong although the disease is common in the cat and dog population. Recently a new Babesia species, Babesia hongkongensis has been identified in the feline population. ${ }^{10}$ The prevalence of this new local species is low among free-roaming cats in Hong Kong and the pathogenicity in pet cats is unknown.

The clinical presentation of human babesiosis varies. Infected patients may present with a mildto-moderate viral-like illness, with gradual onset of chills, sweats, headache, arthralgia, and anorexia. Some patients present with a prolonged course of pyrexia of unknown origin. Physical examination may reveal mild splenomegaly or hepatomegaly. Severe infection generally occurs in those with an underlying immunosuppressed condition, particularly patients with previous splenectomy. Complications of babesiosis include acute respiratory failure, disseminated intravascular coagulation, and multi-organ failure. ${ }^{3}$

Combination therapy with atovaquone and azithromycin is the treatment of choice for mildto-moderate Babesia infection. In severe cases, the use of clindamycin and quinine is recommended. In general, the combination of atovaquone and azithromycin is better tolerated with fewer adverse effects. ${ }^{11}$ All doses of antimicrobial therapy are administered for 7 to 10 days. For severely immunocompromised patients with persistent relapsing infection, a longer duration of at least 6 weeks' treatment is recommended, continuing for 2 weeks after blood smears become negative for Babesia. For fulminant cases, exchange transfusion may be required. ${ }^{2,12}$

\section{References}

1. Wong WS, Chung JY, Wong KF. Images in haematology. Human babesiosis. Br J Haematol 2008;140:364.

2. Vannier E, Krause PJ. Human babesiosis. N Engl J Med 2012;66:2397-407.

3. Vannier E, Gewurz BE, Krause PJ. Human babesiosis. Infect Dis Clin North Am 2008;22:469-88, viii-ix.

4. Teal AE, Habura A, Ennis J, Keithly JS, Madison-Antenucci S. A new real-time PCR assay for improved detection of the parasite Babesia microti. J Clin Microbiol 2012;50:9038.

5. EL-Bahnasawy MM, Khalil HH, Morsy TA. Babesiosis in an Egyptian boy acquired from pet dog, and a general 
review. J Egypt Soc Parasitol 2011;41:99-108.

6. Soares AO, Souza AD, Feliciano EA, Rodrigues AF, D'Agosto M, Daemon E. Evaluation of ectoparasites and hemoparasites in dogs kept in apartments and houses with yards in the city of Juiz de Fora, Minas Gerais, Brazil [in Portuguese]. Rev Bras Parasitol Vet 2006;15:13-6.

7. Földvári G, Farkas R. Ixodid tick species attaching to dogs in Hungary. Vet Parasitol 2005;129:125-31.

8. Prusinski MA, Kokas JE, Hukey KT, Kogut SJ, Lee J, Backenson PB. Prevalence of Borrelia burgdorferi (Spirochaetales: $\quad$ Spirochaetaceae), Anaplasma phagocytophilum (Rickettsiales: Anaplasmataceae), and Babesia microti (Piroplasmida: Babesiidae) in Ixodes scapularis (Acari: Ixodidae) collected from recreational lands in the Hudson Valley Region, New York State. J Med
Entomol 2014;51:226-36.

9. Thematic Household Survey Report No. 48. Census and Statistics Department, Hong Kong SAR Government 2011. Available from: http://www.statistics.gov.hk/pub/ B11302482011XXXXB0100.pdf. Accessed Feb 2016.

10. Wong SS, Poon RW, Hui JJ, Yuen KY. Detection of Babesia hongkongensis sp. nov. in a free-roaming Felis catus cat in Hong Kong. J Clin Microbiol 2012;50:2799-803.

11. Krause PJ, Lepore T, Sikand VK, et al. Atovaquone and azithromycin for the treatment of babesiosis. N Engl J Med 2000;343:1454-8.

12. Dorman SE, Cannon ME, Telford SR 3rd, Frank KM, Churchill WH. Fulminant babesiosis treated with clindamycin, quinine, and whole-blood exchange transfusion. Transfusion 2000;40:375-80. 